\title{
DETERMINATION OF THERMAL RESPONSE OF CARRARA AND SNEZNIKOVSKY MARBLE USED AS BUILDING MATERIAL
}

\author{
Veronika Petráñováa, ${ }^{a, *}$ Jaroslav Valach ${ }^{a}$, Alberto Viani $^{b}$, \\ Marta Peréz EstéBAnez ${ }^{b}$
}

${ }^{a}$ Institute of Theoretical and Applied Mechanics AS CR, v.v.i., Prosecka 76, Prague, Czech Republic

${ }^{b}$ Institute of Theoretical and Applied Mechanics AS CR, v.v.i., Centre of Excellence TelÄD, Batelovska 485, TelÄD, Czech Republic

* corresponding author: petranova@itam.cas.cz

\begin{abstract}
Physical weathering of marble, widely used as a cladding material on buildings, is one of the most common damaging mechanism caused by anisotropic thermal expansion of calcite grains. The extent of marble deterioration depends mainly on stone fabric and texture. Dry cuboids of Carrara marble and marble from Dolni Morava quarry were subjected to microscopic analysis and thermal cycling, to determine the thermal expansion related to stone fabric and predominant lattice orientation of grains (i.e. texture).
\end{abstract}

KEYWORDS: marble, anisotropic thermal expansion, thermal dilatation.

\section{INTRODUCTION}

Marble has been predetermined as building and decorative natural stone since antiquity because of its good workability and unique visual appearance. These properties are related to the composition of carbonate sediments and to the nature and intensity of the recrystallization process under the regional metamorphosis conditions. Marble is considerably vulnerable to both chemical and physical weathering by reason that this type of stone predominantly consists of carbonate minerals calcite - $\mathrm{CaCO}_{3}$ and dolomite - $\mathrm{CaMg}\left(\mathrm{CO}_{3}\right)_{2}$. Periodic temperature variations, together with changing in moisture can cause serious damage to the stone structure, finally leading to the complete stone decay. The enormous sensitivity of marble to variations in temperature originates in the thermal response of calcite crystals. While the dolomite crystals subjected to thermal cycling expand only, the calcite crystals show anisotropic thermal dilatation introduced by thermal cycles, i.e., it expands along c - axis during heating and contracts in other directions. However, cooling of calcite crystals leads to the opposite effect, i.e., contraction along the $\mathrm{c}$ - axis and expansion in the other directions as is illustrated in Figure 1. Both mechanisms are considered as the major cause of creation and propagation of cracks along the grain boundaries in the stone. Thermal expansion can be expressed using the thermal expansion coefficient $\alpha$, describing the length change per unit of temperature. The coefficient value depends on the considered temperature interval. To quantify the extent of stone elongation, the residual strain $\varepsilon$ is more suitable [1].

The preferred lattice orientation of calcite grains i.e. texture is one of the most important stone characteristics, essentially influencing thermal response in different spatial directions. Marble with strong texture is generally more vulnerable to thermal weathering, which can be enhanced by significant differences between the $\alpha$ values along the c- and a-axis of individual calcite grains [2. Thermal expansion of marble is measurable at low temperatures enabling simulation the climate conditions in the central Europe. Nevertheless, experimentally obtained thermal dilatation values often deviated from calculation based on theoretical models considering only the texture variations in a marble. Another important parameters are grain shapes, grain sizes and the type of grain boundaries because of the strong influence on the rate of stone decay. A certain directional relationship between the shape preferred orientation (SPO) of calcite grains and their lattice preferred orientation (LPO) can extensively intensify the thermal response of marble. For example, marble with LPO parallel to SPO exhibits a strong thermomechanical response because of the large concentration of maximum principal stress in the direction of shape elongation. Thermal stresses during heating can initiate the formation of new cracks or widening of preexisting cracks or pores. Microcracking formation can also be influenced by grain size since the level of marble decay is also connected with the number of adjacent grains and with the grain boundaries 3 5]. However, thermal response and consequently the rate of physical deterioration of marble depends also on other stone characteristics, including the ratio of calcite and dolomite, moisture content, porosity and pore size distribution of the investigated marble 6]. Depending on all the mentioned stone characteristics, the thermal response of marble after cooling down to room temperature can be determined as isotropic or anisotropic, with or without residual strain [1]. 

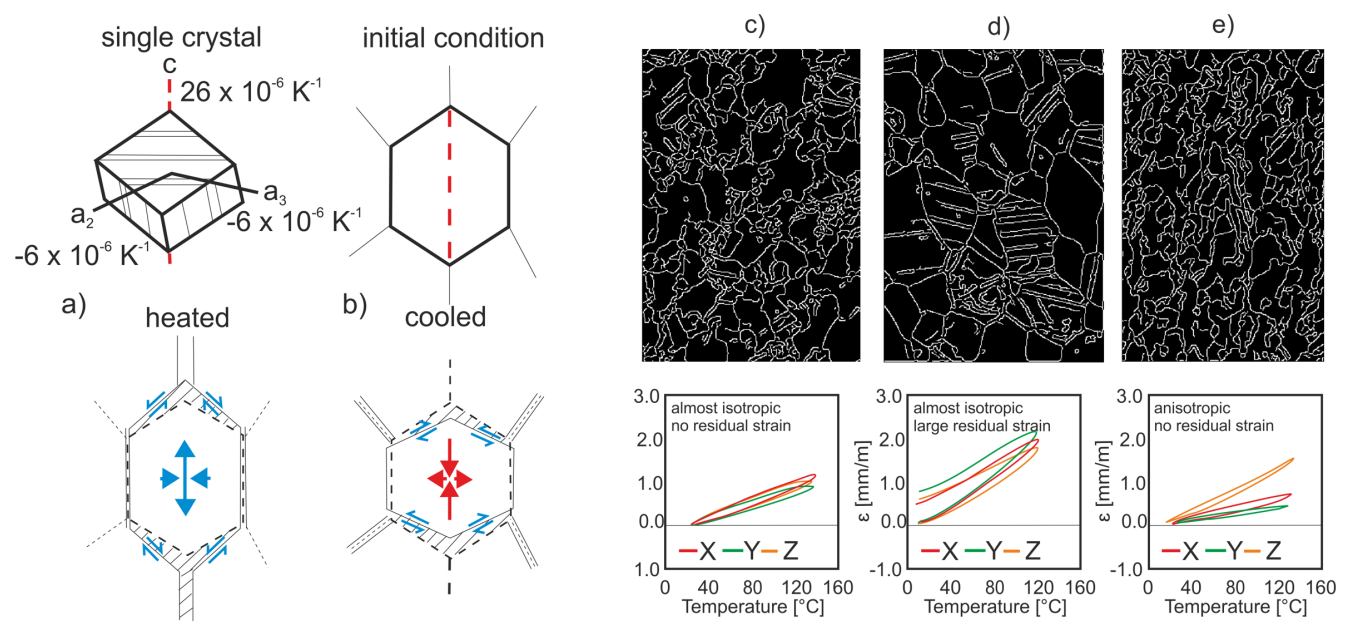

Figure 1. Anisotropic thermal expansion of calcite crystals. Adopted from [1].

\section{Materials and Methods}

Testing of the thermal response was performed on two structurally different marble types. The first one from the Carrara area in northern Italy was chosen for its simple fabric. The second one - Sneznikovsky marble was taken from Dolni Morava quarry in the Czech Republic. The texture as well as the shape and size of grains was investigated by optical microscopy and electron back-scattered diffraction (EBSD) method in a scanning electron microscope (SEM, FEI Quanta 450, FEI corp., USA). For the SEM-EBSD investigations, slide specimens of marble were coated with a thin layer of carbon to protect against specimen charging. To evaluate the dependence of dilatation on the sample's microstructure, two pairs of perpendicular cuboids A-a, B-a, C- 1 and C-4 (6 x 6 × 20 $\mathrm{mm}$ ) were prepared from the original marble blocks. The orientation of the cuboid samples is depicted in Figure 2. Thermal expansion measurements were performed using a vertical dilatometer (L75 PT Linseis corp., Germany). The specimen elongation was measured after each $1{ }^{\circ} \mathrm{C}$ step. The cuboid samples were subjected to heating and cooling cycles, ranging in temperature from -40 to $100^{\circ} \mathrm{C}$. The cycles were repeated 7 times for specimens A-a, B-a and C- 1 and 5 times for specimen C- 4 . The temperature interval was gradually increased for the A-a, B-a and C-1 specimens. The interval for specimen $\mathrm{C}-4$ remained stable in all 5 cycles (from -40 to $100^{\circ} \mathrm{C}$ ). The values for the thermal expansion coefficient $\alpha$ values were calculated using equation (1). The length change in $\triangle L$ was determined within a temperature interval $\triangle T$, from $18^{\circ} \mathrm{C}$ to the maximum temperature in the considered cycle, i.e. for cycle 1 , the maximum temperature was $33^{\circ} \mathrm{C}$, whereas for cycle 7 , it was $100^{\circ} \mathrm{C}$. To determine $\alpha$, only a positive temperature range was selected, because the results from the range below the freezing point were not reliable.

$$
\alpha=\frac{\triangle L}{L \triangle T}
$$

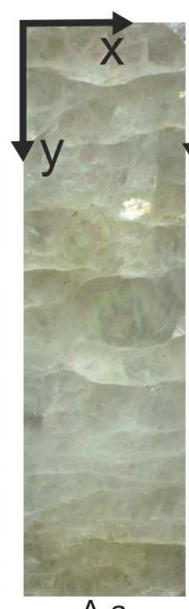

A-a
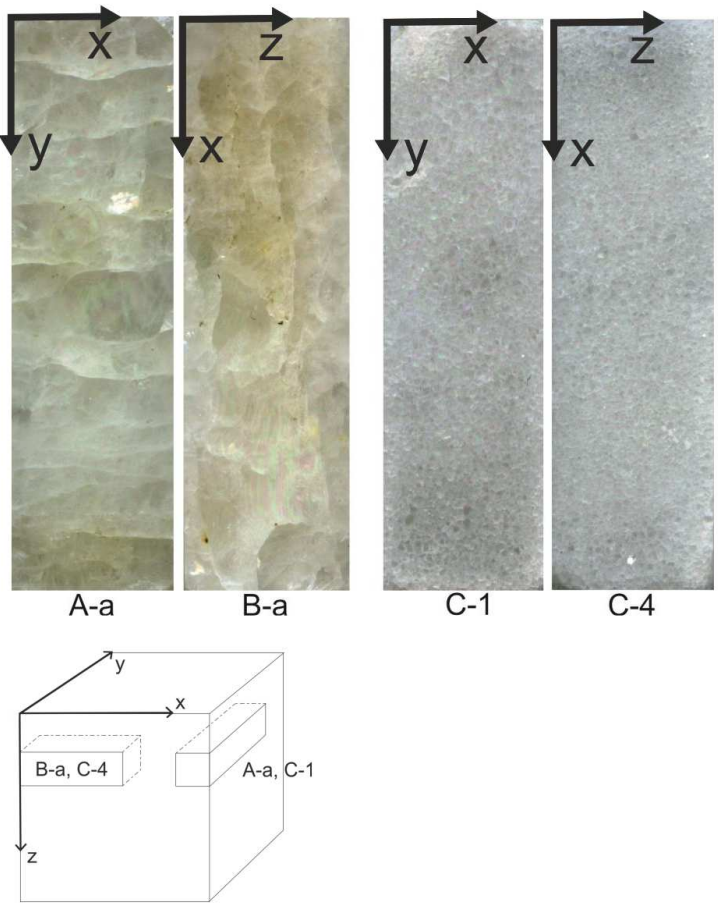

Figure 2. Orientation of cuboid specimens, A-a and $\mathrm{B}-\mathrm{a}$ is Sneznikovsky marble and C-1 and C-4 is Carrara marble.

The symbols and their physical meanings are listed at the end of the paper.

\section{Experimental Results}

Based on optical and SEM-EBSD observations, the Carrara marble exhibits a weak texture in both directions ( $\mathrm{x}-\mathrm{y}$ and $\mathrm{x}-\mathrm{z}$ ). Specimens $\mathrm{C}-1$ and $\mathrm{C}-4$ contain calcite grains with a nearly uniform size of around $0.3 \mathrm{~mm}$ with straight polygonal grain boundaries and no shape preferred orientation. Contrary to Carrara, Sneznikovsky marble exhibits cracking, predominantly on planes parallel to the $\mathrm{x}-\mathrm{y}$ plane. The microfabric of 


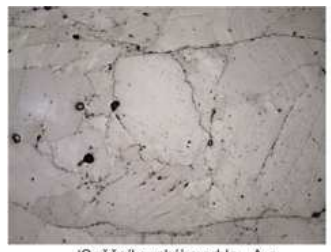

'Snęžnikovsky̆ marble - A-a

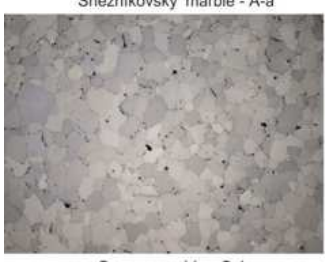

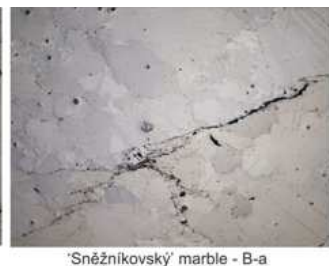

'Snēżnikovskÿ marble - B-a

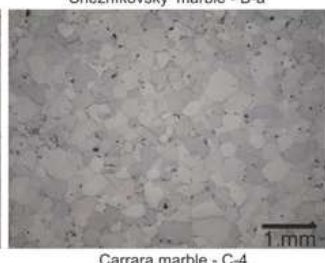

a

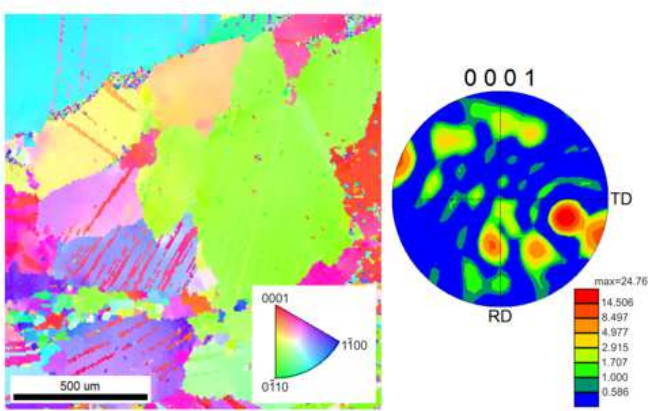

b

FiguRE 3. a - microfabric of investigated samples, b - orientation of calcite grains in B-a sample.

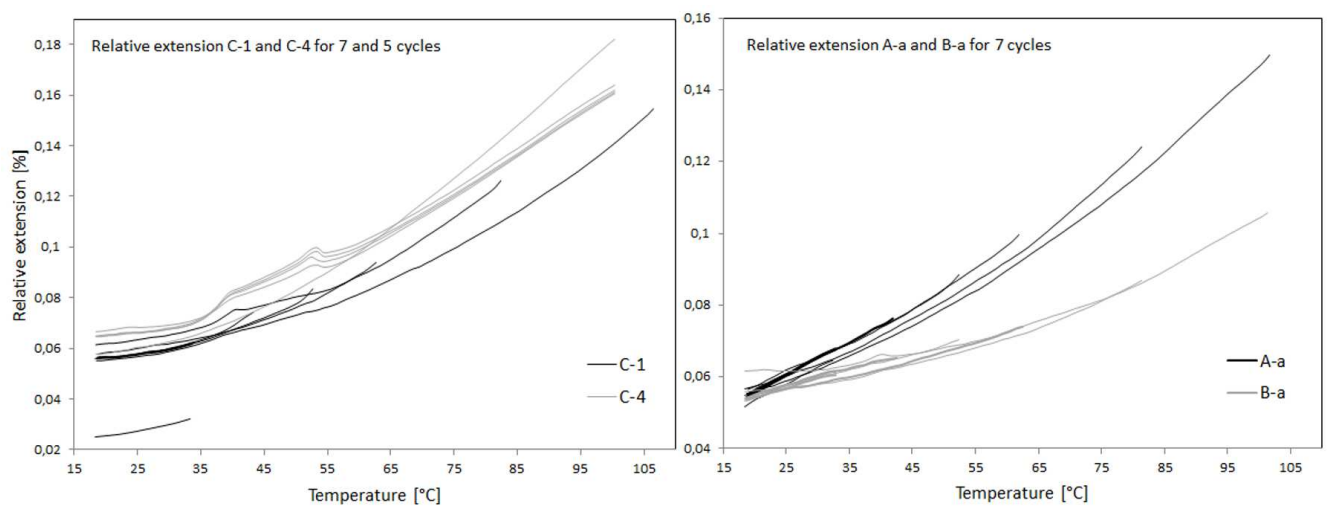

FIGURE 4. Dependence of relative extension on the temperature.

the investigated marble types is illustrated in Figure 3. The size of the calcite grains in the A-a and B-a specimens is not uniform; grains in sizes up to $4 \mathrm{~mm}$ with sutured grain boundaries can be found. As in the Carrara specimen, both perpendicular planes of Sneznikovsky marble contain grains with no shape preferred orientation.

The elongation of the cuboid specimens was expressed as relative extension, i.e. percentage difference between $\triangle T$ for each temperature step and original length of the specimen. The highest relative extension of $0.18 \%$ was observed in $\mathrm{C}-4$ at $100{ }^{\circ} \mathrm{C}$ in the first cycle. In the other cycles (2-5) the value was equal to $0.16 \%$. Specimen C-1 showed an increasing trend over the temperature and reached its maximum relative extension of $0.14 \%$ at $100{ }^{\circ} \mathrm{C}$. Regarding the coefficient $\alpha$, specimen $\mathrm{C}-4$ also showed the highest average value of $12.5 \cdot 10^{-6} K^{-1}$. Specimen $\mathrm{C}-1$ achieved the most significant difference in $\alpha$, varying from $3.9 \cdot 10^{-6} K^{-1}$ to $11.3 \cdot 10^{-6} K^{-1}$. The results are illustrated in the Figures 4 and 5 . The first cycle of the measurements performed on the specimen $\mathrm{C}-1$ was excluded from the results. Values obtained from the first cycle performed in C-1 specimen weren't included to the results.

During the 7 cycles in specimens A-a and B-a relative elongation also showed an increasing trend, but the maximum values were more different than in the Carrara marble. At $100{ }^{\circ} \mathrm{C}$ in cycle 7 , the relative

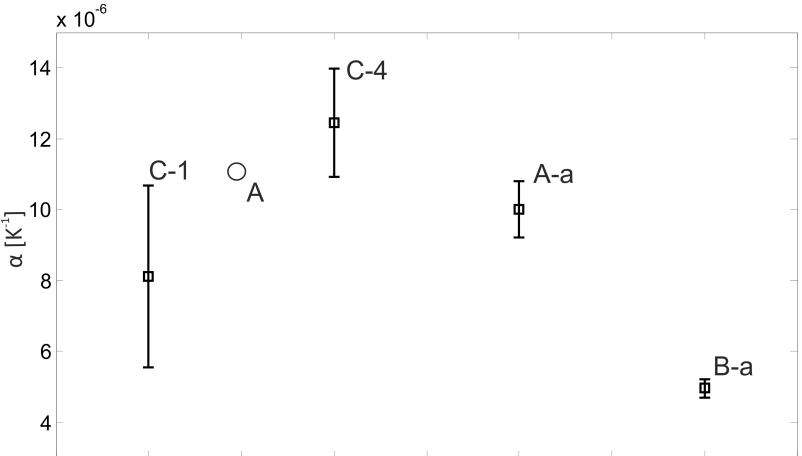

Figure 5. Thermal expansion coefficient $\alpha$ of investigated specimens, loaded in the $18-100^{\circ} \mathrm{C}$ temperature interval. The value marked "A" represents an average value of $\alpha$ determined by [7] on large set of marble specimens.

extension in specimen A-a was equal to $0.15 \%$ while in B-a it was just $0.10 \%$. The $\alpha$ coefficients determined for the Sneznikovsky marble were not as variable as in the Carrara type. In the A-a sample, $\alpha$ reached an average value of $10 \cdot 10^{-6} K^{-1}$ and in the B-a sample of $5 \cdot 10^{-6} K^{-1}$. Based on the relative extension difference between corresponding cycles, an $\alpha$ variation of $5 \cdot 10^{-6} K^{-1}$ was determined, which can be attributed to the observed anisotropy in the Sneznikovsky mar- 
ble, i.e. the $\mathrm{x}-\mathrm{y}$ orientated plane in specimen A-a was more fissured.

\section{Conclusions}

It can be concluded that simultaneous microscopic and dilatometry investigations can help in elucidation of thermally induced degradation of marbles. Based on the results, the thermal response and generation of damage caused by accumulation of residual strains related to stone fabric and texture in investigated marbles will be determined on a larger set of perpendicular specimens, heated and cooled in the positive range of temperatures (i.e. from 20 to $100{ }^{\circ} \mathrm{C}$ ). Investigations carried out on both specimen types reveal an increasing rate of thermal expansion with increasing temperatures. In presence of a temperature gradient, this characteristic can contribute to the well known bowing effect on marble slabs.

\section{LIST OF SYMBOLS}

$\alpha$ Thermal expansion coefficient $\left[\mathrm{K}^{-1}\right]$

$\triangle L$ Difference between the actual specimen length and the length at the room temperature $[\mathrm{m}]$

$L \quad$ Length of the specimen at the room temperature $[\mathrm{m}]$ $\triangle T$ Temperature difference between the actual and the room temperature $[\mathrm{K}]$

\section{ACKNOWLEDGEMENTS}

The research has been supported by Czech Science Foundation (Project no. P105/12/G059).

\section{REFERENCES}

[1] M. Steiger, A. Charola. Weathering and deterioration. In The Stone in Architecture, chap. 4., Springer-Verlag, 2011. DOI:10.1007/978-3-642-14475-2_4

[2] S. Siegesmund, K. Ullemeyer, T. Weiss, E.K. Tschegg Physical weathering of marbles caused by anisotropic thermal expansion. Inter J Earth Sci 89(1):170-182, 2000 .

[3] V. Shushakova, E.R. Fuller Jr, S. Siegesmund. Influence of shape fabric and crystal texture on marble degradation phenomena:simulations. Env Earth Sci 63(7-8):1587-1601, 2011. DOI:10.1007/s12665-010-0744-7

[4] B. Leiss, T. Weiss. Fabric anisotropy and its influence on physical weathering of different tyes of Carrara marbles. J Struct Geol 22(11-12):1737-1745, 2000.

[5] U. Akesson, J.E. Lindqvist, B. Schouenborg, B. Grelk. Relationship between microstructure and bowing properties of calcite marble claddings. Bull Eng Geol Env 65(1):73-79, 2006.

[6] E. Cantisani, E. Pecchioni, F. Fratini, C.A. Garzonio, P. Malesani, G. Molli. Thermal stress in the Apuan marbles: Relationship between microstructure and petrophysical properties characteristics. Inter J Rock Mech Min Sci 46(1):128-137, 2009. DOI:10.1016/j.ijrmms.2008.06.005

[7] A. Zeisig, S. Siegesmund, T. Weiss. Thermal expansion and its control on the durability of marbles. In The Natural Stone, Weathering Phenomena, Conservation Strategies and Case Studies, chap. 2., The Geological Society of London, 2002. 